\title{
Semantic change
}

\author{
Josep Martines \\ Sandra Montserrat \\ Universitat d'Alacant. ISIC-IVITRA \\ josep.martines@ua.es \\ sandra.montserrat@ua.es
}

The main topic of this issue of Catalan Journal of Linguistics, semantic change, is probably one of the areas of linguistic research gaining more prominence over the last years. This fact is possibly due to two circumstances. a) On the one hand, to the development of the meaning-oriented and usage-based approaches to language, which take place mainly (although not exclusively) within the theoretical framework of Cognitive Linguistics and Pragmatics. And, b) on the other, to the development of text corpora (representing both Old and Contemporary language in written or oral form), driven by the necessity to approach the communicative language usage.

That maxim by which «Chaque mot a sa histoire», ascribed to Jules Guilliéron (beginning $20^{\text {th }}$ Century), seems to have very much affected the prevailing conception on semantic change during a long period of time. Therefore, semantic change has been traditionally conceived as the land of curiosities and irregularities. However, this view has changed in the last decades, where the aim to describe the trends and regularities it shows - if not the laws governing it - has become the focus, providing an essential contribution to the study of semantic change.

A set of new questions regarding emergence and disappearance of meanings have been posed: according to which mechanisms, in which contexts and under which conditions, where, when and — as far as possible to determine - why these new senses emerge, disappear or are pushed aside? The aim to answer this set of questions led to the redefinition of meaning. This concept has now been extended beyond the boundaries of lexical semantics and has reached the fields of morphology, syntax and phraseology. As a consequence, other areas devoted to the study of communication and sociocultural context, in which the speech act takes place and new meanings emerge, become also involved in semantic analysis. These areas are basically Pragmatics, Sociolinguistics and Cultural History. We could even claim that the study of language, its evolution and its usage and forms essentially consist in studying the constant emergence of meaning.

The present issue of Catalan Journal of Linguistics gathers contributions on the main topics related to contemporary semantics. We list them now, before briefly summarizing the contents of each paper: a) polysemy, polysemysation, synonymy, 
semantic and lexical lectal variation; b) metaphor and metonymy, subjectivation and intersubjectivation as mechanisms and factors of semantic change, respectively; c) pragmatic inference as a true trigger of semantic change; d) emergence, understanding, spreading and semantization of new meanings; e) grammaticalization, phraseologization and constructionalization as semantic changes; and, finally, f) inner (paradigmatic relations) and outer conditions (pragmatic, sociolinguistic and cultural factors) of semantic change. Grammaticalization, the Invited Inference Theory of Semantic Change (IITSC), Prototypicality Effects, pragmatic enrichment, the Theory of Conceptual Blending and image schemas constitute the theoretical background of these ten papers, where concrete cases of semantic change in Catalan, Spanish, Italian and Portuguese are analysed.

Jordi Antolí analyses the evolution of the periphrasis voler 'to want' + Infinitive, from Medieval Catalan until our days. He shows the path followed by this construction, which started as an aspectual periphrasis indicating imminence and is nowadays a saturated construction basically used with the infinitives ploure 'to rain' and caure 'to fall down'. The emergence of the epistemic/evidential sense, the one remaining in contemporary uses, takes place during the process of subjectification and constructionalization. To describe this process of semantic change, the Invited Inference Theory of Semantic Change (IITSC) is used. Within this theoretical framework, the gradual evolution of the construction is shown, shifting the focus from the initial prospective aspect, implying imminence, to the ending epistemic/evidential value.

Laura Baranzini and Claudia Ricci study the semantic and pragmatic values of the Italian imperfect tense, as well as its genesis. They carry out an accurate analysis of contexts and nuances regarding the usage of the imperfect tense and show to what extent those nuances are bound to the context. They propose a set of traits that, after undergoing the process of pragmatic enrichment, would acquire the current range of senses displayed by this tense. They set out a proposal considering three essential meanings of the imperfect tense: the narrative meaning, the evidential meaning and the activation of a preliminary phase in relation to the event. Since these meanings are pragmatically activated, a close relation between pragmatics and semantics is established.

Ricardo Maldonado and Rocío Guzmán conduct a diachronic study on luego entonces to show how it becomes an argumentative marker with a concrete pragmatic value. Note that this marker is normally used to indicate the hearer that a statement is irrefutable. They analyse luego entonces applying the conceptual fusion and describe it as a blend combining two consecutive markers, the first one being more bleached than the second. This paper points out the historical period when both blended elements underwent semantic change and describes its process of fixation. The addition of entonces would bring back the consecutive intersubjective reading that luego had lost over time. This process is clearly to see, especially in argumentative texts, where the key role of intersubjectivity and pragmatic relation between speaker and hearer can be observed.

Josep Martines gives notice of an unknown or ignored fact: the existence of a reprise evidential conditional in Old Catalan. This reading is evidently observed 
in texts from the beginning of the $14^{\text {th }}$ century and the Early Modern period. He connects this reading with the subjectification and intersubjectification processes underwent by the future and the conditional (understood as a future-of-the-past) tenses from the end of the $13^{\text {th }}$ century. This could explain the emergence of several uses of both verb tenses in this period: such as epistemic future and conditional, concessive conditional, the mirative condicional, the conjectural conditional for response elicitation, and, finally, the conjectural conditional in reported contexts. According to him, this latter reading should have opened the path for the emergence of the reprise evidential conditional in the next century (14 ${ }^{\text {th }}$ century). IITSC and pragmatic context analysis - focusing on (inter)subjectification - have proved to be useful theoretical tools to describe and explain meaning evolution and grammaticalization.

Manuel Pérez-Saldanya studies the evolution of the demonstrative adverbs system in Catalan, comparing it to the Spanish system within the Latin and Romance paradigm. He explains the process underwent by an initially binary deictic system, becoming ternary in both languages and subsequently turning into a new binary system, at least in a part of the Catalan language. He highlights pragmatic factors, such as subjectivation, as well as the influence of functional and formal relations on the paradigm of demonstrative adverbs and pronouns. He shows that these relations can act as triggers of semantic change, in a case that might be considered inconsistent with one of the essential features of grammaticalization, namely unidirectionality.

Joan-Rafael Ramos carries out a semantic structure analysis on the verb pegar and its derivatives (pegar 'hit/stick', apegar 'stick' and empegar 'stick'), focusing on the Catalan spoken in the area of Valencia. He highlights the role of metonymy as a mechanism of semantic change and its importance to accurately describe the semasiological complexity of these verbs. IITSC, image schemas of path and prototypicality effects are the theoretical background for this analysis. The author also suggests the importance of considering — in future research works — the influence of language contact (in this case, Aragonese and Castillian Spanish) on the studied uses.

Elena Sánchez López focuses on the genesis process (phraseologization) of the Catalan phraseological unit «al peu de la lletra» ('to the foot of the letter', meaning literally). She establishes a theoretical framework, providing a definition for the concept of phraseological unit and including cognitive-oriented semantic and pragmatic conceptual tools, which had not been applied to phraseology before. She compares the grammaticalization process to that of phraseologization, focusing on the role played by inference (or conversational implicature) in the emergence of phraseological meaning. For this purpose, she establishes and accurately describes the stages of the phraseologization process. Thus showing that, although phraseology and the emergence of phraseological meaning have traditionally been considered to be anomalous, they actually respond to the same semantic changes undergone by other language elements.

Andreu Sentí describes the grammaticalization and semantic change process undergone by the periphrasis deure ('must') + Infinitive. It initially presented a deontic sense and developed two different readings, an inference evidential value 
and a temporal posteriority or future value, during the $12^{\text {th }}$ and $13^{\text {th }}$ centuries. This process follows a conceptual schema with a more subjective configuration (scheduled future and imminent future). It develops a pattern with well-defined stages within the grammaticalization path: NECESSITY > SCHEDULED FUTURE > IMMINENT FUTURE. This paper accurately describes the progression of the future reading by deure until the $16^{\text {th }}$ century, due to the progressive attenuation of the source of conceptual force and the increasing subjectification of the conceptual schema. This scenario changed from the $16^{\text {th }}$ on, where the usage of deure with a future value dramatically decreased. It is highly probable that the fact that this periphrasis did not completely develop a subject-oriented future meaning interrupted this process. The spread of the periphrasis haver (a/de) ('have (to/ of)) + Infinitive with future meanings may have also contributed to this interruption.

Augusto Soares da Silva carries out a study on lexical synonymy focussing on two concrete cases: the evolution of the verb deixar 'to leave, to let' from Old to Modern Portuguese and its concurrence with two competing synonyms (abandonar 'to abandon' and permitir 'to allow'); and the comparative analysis on a great amount of terms related to football and clothing in European and Brazilian Portuguese in the last 60 years. This paper is a contribution to the conceptual analysis of Cognitive Linguistics, since it includes essential elements of Cognitive Sociolinguistics. Therefore, he takes into consideration the social factors conditioning meaning emergence and change as well as lexical selection and lectal variation. He outlines an approach to synonymy, synonym competition and lectal variation that goes far beyond the postulates of the structuralist model.

Alicia Urquidi analyses the emergence of meaning, more concretely, the meaning construction regarding innovative metaphorical or metonymical expressions, which may subsequently be integrated in the language system and become part of it. She bases her analysis on a collection of economic texts in Spanish. In this paper, a classification of types and processes of creative metaphors is established and the path towards lexicalization is described. The Conceptual Blending Theory and the study of pragmatic implicatures prove to be useful conceptual tools to describe the processes of metaphor construction and understanding. The degree of relevance and iconicity are essential factors to the processes of comprehension of creative utterances via blends in their pragmatic contexts. 